BULLETIN Bulletin hispanique

HISPANIQUE Université Michel de Montaigne Bordeaux

$120-2$ | 2018

Varia

\title{
Maricruz Castro Ricalde, Mauricio Díaz Calderón and James Ramey (eds), Mexican Transnational Cinema and Literature
}

Oxford, Peter Lang, 2017

Gabrielle Pannetier Leboeuf

\section{OpenEdition}

Journals

Edición electrónica

URL: https://journals.openedition.org/bulletinhispanique/7482

DOI: 10.4000/bulletinhispanique.7482

ISSN: $1775-3821$

Editor

Presses universitaires de Bordeaux

Edición impresa

Fecha de publicación: 10 diciembre 2018

Paginación: 711-716

ISBN: 979-10-300-0337-6

ISSN: 0007-4640

\section{Referencia electrónica}

Gabrielle Pannetier Leboeuf, «Maricruz Castro Ricalde, Mauricio Díaz Calderón and James Ramey (eds), Mexican Transnational Cinema and Literature», Bulletin hispanique [En línea], 120-2 | 2018, Publicado el 10 diciembre 2018, consultado el 08 enero 2022. URL: http://journals.openedition.org/ bulletinhispanique/7482 ; DOI: https://doi.org/10.4000/bulletinhispanique.7482

Este documento fue generado automáticamente el 8 enero 2022.

Tous droits réservés 


\title{
Maricruz Castro Ricalde, Mauricio Díaz Calderón and James Ramey (eds), Mexican Transnational Cinema and Literature
}

Oxford, Peter Lang, 2017

\author{
Gabrielle Pannetier Leboeuf
}

\section{REFERENCIA}

Maricruz Castro Ricalde, Mauricio Díaz Calderón and James Ramey (eds), Mexican

Transnational Cinema and Literature. Oxford : Peter Lang, 2017, 316 p. - ISBN

978-1-78707-066-0

1 ¿Cómo pensar la cuestión nacional en el México en transformación de los siglos XX y XXI? ¿Qué implicaciones tiene el transnacionalismo en un cine y una literatura conceptualizados como mexicanos? Maricruz Castro Ricalde, profesora e investigadora en la Escuela de Humanidades y Educación del Tecnológico de Monterrey, Mauricio Díaz Calderón, profesor e investigador en el departamento de historia de la Universidad de Guadalajara, y James Ramey, profesor e investigador en la Universidad Autónoma Metropolitana - Cuajimalpa, editores del volumen que nos ocupa, se dieron la valiosa tarea de organizar la reflexión colectiva en torno a estas preguntas de apremiante actualidad, y proponen para ello concebir la nación así como las fronteras como conceptos plásticos.

2 Mexican Transnational Cinema and Literature es el primer volumen de la serie de libros «Transamerican Film and Literature», de la editorial Peter Lang International, serie que versa sobre cine y literatura del continente americano. La versión preliminar de los capítulos que componen el libro ha sido presentada bajo la forma de ponencias en la convención anual de 2016 de la Asociación Americana de Literatura Comparada (ACLA), 
que tuvo lugar del 17 al 20 de marzo de 2016 en la Universidad de Harvard, en Cambridge. Veinticuatro académicos provenientes de México, Estados Unidos, Canadá e Inglaterra participaron en doble seminario, y de estas ideas en ebullición nació el proyecto de una serie de libros sobre cine y literatura en el que este volumen se enmarca.

El volumen de más de trescientas páginas aborda de lleno la cuestión de la significación atribuida a lo transnacional y, de forma coextensiva, a los conceptos de «nación» y de «frontera», pensando sus implicaciones en los ámbitos cinematográfico y literario mexicanos. A pesar de que las diferentes contribuciones abarcan principalmente tres periodos diferentes de los siglos XX y XXI -el periodo posrevolucionario (años veinte y treinta), el periodo industrial que coincide cinematográficamente con la Época de Oro (años cuarenta y cincuenta), y el periodo neoliberal (años ochenta hasta la actualidad)-, la coherencia del volumen no se ve afectada por los ocasionales saltos en el tiempo entre los capítulos, y reside principalmente en la preocupación común por cuestionar la fijeza conceptual de la mexicanidad y crear sentido en cuanto a la porosidad de las fronteras nacionales, identitarias y/o genéricas. Rompiendo también con las fronteras lingüísticas, el volumen consta de quince artículos en español y dos en inglés. Asimismo, los agradecimientos, la introducción así como los títulos de las tres secciones del libro son bilingües, en total coherencia con el proyecto transfronterizo y continental del libro.

El libro se divide en tres ejes temáticos: 1) la cuestión de lo transnacional; 2) la nación y lo nacional; 3) las representaciones de lo local frente a lo global. Consta de tres secciones, que versan sucesivamente sobre lo transnacional y lo posmoderno, los tránsitos y los desplazamientos textuales, y las cuestiones de migración y de fronteras. Mientras que la primera sección, más apegada a la filosofía, replantea ontológicamente la definición de lo nacional y las cuestiones identitarias en el cine y la literatura mexicanas del siglo XXI, la segunda sección se interesa por las influencias estéticas foráneas y hace dialogar el cine con otros géneros artísticos para reflexionar sobre la «mexicanidad»y sobre la creación, a veces estereotipada, de un imaginario colectivo nacional en la primera mitad del siglo XX. La última y tercera sección, por su parte, se centra en algunos textos fílmicos de la segunda mitad del siglo XX y del siglo XXI para reflexionar sobre las migraciones y las redefiniciones identitarias en su relación con las fronteras, ya sean estas geográficas, culturales o de género.

5 La brillante introducción de los tres editores, tras recordar que la nación no es más que una categoría de representación, plantea preguntas esenciales y comprometedoras que nutrirán las reflexiones del lector a lo largo de su recorrido por los diecisiete capítulos del volumen. ¿Qué significa la categoría de cine o literatura «nacionales», qué impacto tiene el cruce de fronteras para el arte, y bajo qué criterios se puede considerar una película o una obra literaria «mexicana»? Con la emergencia de una cultura fronteriza compartida de ambos lados del muro, ¿basta el origen geográfico de un director o de un escritor para determinar la mexicanidad de una obra artística? ¿Será más bien el lugar de creación del proyecto artístico el que determine su carácter mexicano? ¿Serán sus temáticas? ¿su estética? Es a la luz de esta serie de preguntas planteadas en la introducción como la lectura de los capítulos de este volumen colectivo cobra pleno sentido.

6 La primera sección sobre lo transnacional y lo posmoderno cuestiona hábilmente la pertinencia de las habituales clasificaciones nacionales del cine en el contexto actual de 
globalización de los circuitos de producción, distribución y exhibición (Ramey), contexto caracterizado por la aminoración de la financiación nacional y por la multiplicación de las coproducciones, la relocalización de los talentos y la internacionalización de la recepción y del consumo de las películas. En respuesta a esta clasificación tradicional, Ramey propone el modelo teórico alternativo de cine transnacional, pensado a través del lente posthumanista de Bajtín como un fenómeno metafóricamente biológico y un «lenguaje de heteroglosia» (p. 29). La puesta en jaque del enfoque nacionalista iniciada por Ramey sigue con una lectura de la alegoría como estrategia de reconocimiento y de promoción del diálogo intercultural y como agente discursivo de una «ecología literaria» (p. 33) global heterogénea (Bernal). A partir de dos casos literarios concretos de los quince últimos años, Bernal propone la creación de un espacio simbólico alternativo a la nación con la destrucción del cosmopolitismo moderno en El fin de la locura (2003) y con la desterritorialización del deseo colectivo en Arrecife (2012). Las «tramas de globalización» (p. 35) estudiadas por Bernal nos llevan luego al «perspectivismo plural» (p.51) fomentado por las preferencias estéticas y técnicas en Batalla en el cielo (2005), de Carlos Reygadas. Este perspectivismo plural, también redefinidor de lo nacional, se aleja de las perspectivas unificadas como la bandera para repensar la nación más bien a partir de otro locus visibilizado por la fragmentación del montaje y la opacidad: los cuerpos de los sujetos (Choi). Profundizando la relación que Reygadas establece entre la redefinición identitaria y la composición audiovisual, se analiza a continuación la experiencia de la impermanencia y de la transitoriedad de los seres y de la materia propiciadas por la materialidad del filme en Post Tenebras Lux (2012) (Álvarez-Olarra). La reconceptualización de la identidad y de lo nacional que se opera en esta sección se cierra con el estudio de la (de)construcción que hace Esther Seligson de ella misma y del concepto de identidad nacional en sus memorias autobiográficas Todo aquí es polvo (2010), pensando la apropiación cultural lingüística y las problemáticas de género vividas por la autora a partir de las herramientas teóricas proveídas por la Poética de la Relación de Glissant (Parra Lazcano).

7 La sección siguiente, sobre tránsitos y desplazamientos textuales, se abre con la afirmación de la existencia de un diálogo y de una reciprocidad entre el cine mexicano de la Época de Oro (más específicamente las rancheras), los cromos de calendarios y las canciones relacionadas con ambas plataformas. Ante las tensiones provocadas por las transformaciones culturales a escala nacional, se plantea que cada una de estas representaciones artísticas fortalece desde lo popular el imaginario sobre la mexicanidad y la idealización del proyecto nacional unificado gracias a su iconografía, así como los estereotipos esencialistas y homogeneizantes (Castro Ricalde). Continuando la reflexión sobre la construcción del imaginario colectivo, se analizan luego la corporalización de las representaciones y la interpelación de un público nacional y popular en las escenificaciones culturales discursivas y visuales que se hicieron de la Noche Mexicana de 1921 bajo el ángulo de la edificación del proyecto nacional y de la reinvención performática y polifónica de lo mexicano y de la idea de nación en el espacio público (Cuellar). Siempre siguiendo el hilo temático de la reconceptualización de lo «mexicano», se piensa también la creación de estereotipos nacionales -y de arquetipos mexicanos negativos como el salvajismo y la inferioridaden el cine de la Revolución mexicana de los años treinta «por la urgencia de interpretar el acontecimiento de la revolución» (p. 141) en un contexto de tensiones entre la modernidad y la tradición (Belmonte Grey). En diálogo con la reflexión iniciada por 
Castro Ricalde sobre la capacidad de los géneros de influenciarse mutuamente, otro capítulo se centra en la relación compleja que teje el literato Mariano Azuela con el cine de la Época de Oro en todos sus altibajos, tanto en su distancia inicial con el cine como en sus intentos no siempre logrados de acercarse al mundo de la adaptación, de entender los códigos cinematográficos y el público, y también en la influencia que tuvo la industria cinematográfica en una de sus últimas novelas escrita específicamente para cine (Vázquez Mantecón). Retomando la reflexión sobre lo que constituye «la mexicanidad», se lleva a cabo luego una comparación formal e ideológica entre el cine de México y el de los Estados Unidos entre los años 40 y 50 a partir del análisis de escenas paradigmáticas seleccionadas del film noir, de la comedia romántica, del cine musical, del melodrama y del cine social, concluyendo que, a pesar de las convergencias formales en ambos cines nacionales, las ideologías y las apropiaciones genéricas resultan muy diferentes y propias a cada país (Zavala). Frente a esta afirmación de la distinción ideológica entre cines vecinos, el último capítulo de esta sección se interesa por el llamado "cosmopolitismo estético» (p. 192), en términos de Motti Regev. Aborda la posibilidad de cruces e influencias entre estéticas transnacionales (del noir) y otras nacionales por tradición (el melodrama), demostrando, a pesar del fuerte peso de la tradición que se hace sentir a finales de los años 40 y a principios de los 50, la gradual incorporación al cine mexicano de patrones estilísticos foráneos que permiten pensar la nación (Fernández).

8 La tercera y última sección del volumen versa ante todo sobre migración, fronteras e identidad en el contexto neoliberal caracterizado por las dinámicas de globalización. En esta sección se comparan primero la película californiana y chicana El Norte (1983) y la película oaxaqueña Norteado (2009) en su tratamiento del cruce fronterizo ilegal, con la constatación de que si bien la categoría de cine nacional queda limitada para dar cuenta del cine que se produce en la industria cinematográfica globalizada, la identidad cultural de los directores (chicana o mexicana) sí tiene un peso considerable en los recursos formales y en el discurso ideológico movilizados. Efectivamente, la retórica y los recursos estéticos de ambas películas contrastan profundamente pese al contexto de producción y a las temáticas similares en torno a la migración y al sueño americano (Levin Rojo y Aguilar Vera). La globalización acarrea también injusticias y desigualdades en las relaciones entre culturas dentro del espacio nacional; el carácter comprometido del arte permite traspasar algunas de las fronteras que separan las culturas o al contrario visibilizar su existencia. En este sentido, se propone también en esta sección, a partir de categorías lingüísticas puestas a dialogar con secuencias del documental Eco de la montaña (2014) de Nicolás Echevarría, comprender el documental como un lenguaje y un discurso cinematográfico que, en tanto construcción, incide desde los signos en la realidad histórica y política (Salgado Bautista). La cuestión de la migración evocada por Levin Rojo y Aguilar Vera se retoma para desarrollar la idea de explotación que le es intrínsecamente asociada en México y especialmente en la llamada Faja de Oro; desde un corpus compuesto por las películas Rosa blanca (1961) y La jaula de oro (2013), se establece un paralelo entre la explotación del trabajador nacional por empresas extranjeras percibidas como invasoras entre finales del siglo XIX y 1938, y la explotación actual de migrantes centroamericanos por los mexicanos (Domínguez Cáceres). Un análisis de la significación identitaria de autorrepresentaciones pictóricas como los murales callejeros, las imágenes de santos caseros y las leyendas ancestrales en la cinta La misma luna (2007) permite profundizar la compleja relación de los mexicanos en Estados Unidos, prestando especial atención a los roles femeninos de la 
mujer hispana en los Estados Unidos apegados a los íconos mexicanos, mexicoamericanos y chicanos de identidad femenina como la Virgen de Guadalupe, la Malinche y la Llorona (Zavala-Garrett). El enfoque de género y la sensibilidad hacia las problemáticas vividas por mujeres en torno a la (re)definición nacional de su identidad se mantienen luego hasta el final del volumen. Después de leer el cuerpo femenino juarense en Backyard: El traspatio (2008) como una alegoría o metáfora del territorionación mexicano cosificado, usado, vejado y desechado por las grandes empresas transnacionales, por el aparato de Estado (masculino) y por la sociedad patriarcal (Vargas Amésquita), el volumen termina con un estudio de las mutaciones de la identidad nacional en la cinta Espiral (2009), sobre todo de las identidades de género y del tejido social, mutaciones instigadas por las demandas de globalización y pensadas desde las migraciones y las concepciones circulares del tiempo (Díaz Calderón).

En resumidas cuentas, este volumen, sin proponer una respuesta definitiva a lo que significa ser mexicano en el cine y la literatura de los siglos XX y XXI, rompe de manera inteligente con las ideas preconcebidas sobre la mexicanidad y abre paso a una redefinición más dinámica de la nación y de la identidad, teniendo en cuenta las complejas relaciones fronterizas y las cuestiones migratorias. A pesar de la diversidad de autores y de objetos artísticos estudiados, las reflexiones que nacen de los capítulos dialogan entre sí con fluidez; la reunión de las diecisiete contribuciones resulta entonces fructífera y permite una comprensión diacrónica y más profunda de las interrelaciones entre cine, literatura y construcción de la nación. Un notable esfuerzo de contextualización histórica, política y cultural atraviesa los capítulos, dándole rigor y sustancia al análisis propuesto por los diferentes autores. Además, cada capítulo está enriquecido con abundantes notas a pie de página y el volumen provee una bibliografía aprovechable sobre los temas del nacionalismo, del transnacionalismo y de la migración.

Mexican Transnational Cinema and Literature lleva más allá la reflexión sobre la dimensión transnacional del arte en contextos de globalización que otros volúmenes colectivos como México imaginado: Nuevos enfoques sobre el cine (trans)nacional (2011) ${ }^{1}$ habían iniciado antes, extendiendo la cuestión también a la literatura, que conoce cambios de la misma índole. En un contexto político en el que se cuestiona la colaboración intercontinental americana, los editores han apostado, con este primer volumen de la serie sobre cine y literatura transamericanos, por una reafirmación de la importancia del proyecto cultural cinematográfico y literario americano. Y su propuesta resulta más que convincente.

\section{NOTAS}

1. Claudia Arroyo, James Ramey y Michael Schuessler (eds). México imaginado: Nuevos enfoques sobre el cine (trans)nacional. México DF: CONACULTA y UAM, 2011. 


\section{AUTORES}

\section{GABRIELLE PANNETIER LEBOEUF}

Crimic-sorbonne 